\title{
Open University Center of the Pontifical Javeriana University, Colombia.
}

\author{
Omayra Parra de Marroquin \\ Lina Claricia Corredor Moyano
}

\begin{abstract}
According to García Canclini, there is the assumption that Colombia is a hybrid society. Upon this standpoint, and within a traditional higher education structure characterized by being fundamentally conventional or campus based, the Open University Center of the Pontificia Universidad Javeriana was created as an education program that breaks with every traditional scheme, which in turn, encourages a new learning pattern. The Open University Center emerges as a "social response" focused on the "here and now" of today's society in Colombia.

The Javeriana University (a hybrid university) can be placed in this context as well as the Open University Center, as a part of it. Since its creation, through its programs this center offers education to the most vulnerable of Colombia's population, contributing to raise their quality of life.

In this article, the authors outline the Open University Center's place in the University's context: its historical development and its structure concerning students, programs, regulations, infrastructure and technological equipment. They also identify the implications and relationships of the traditional education proper of the Pontificia Universidad Javeriana, as well as the projection and contributions of the Open University Center to the University's future in the pedagogical order of distance education towards virtual education.
\end{abstract}

According to Garcia Canclini (1990) Latin American countries are a synthesis that intertwines vestiges of indigenous cultures and colonial Catholic Spanish traditions with current political, educational, and communication developments. From this dynamic, traditional cultures are melded with modern-day influences to create a modern day culture in which to be educated means one knows how to incorporate advances in technology with art and literature of the vanguard to create a traditional setting of social privilege and symbolic distinction. The multi-temporal heterogeneity of modern culture, therefore, is a consequence of an historical condition in which modernization complements, rather than replaces, the traditional and ancient (Garcia Canclini, 1990, p. 45).

From the foregoing, we can say that Colombia is comprised of a society that has, in the past, whole-heartedly embraced traditional higher education structures. 
As a result, new educational programs that fundamentally break with traditional expectations, well necessary and welcomed, signal a fundamental shift in this country. One such fundamental shift can be witnessed in a new program called Distance Education for Primary Education Teachers, a program designed specifically to seek out and address problems experienced by teachers in their

classrooms. Developed for teachers who cannot move to the city (location of the University) to pursue formal higher education studies, this distance education program has altered in the perception of what university is all about, thereby creating a viable and alternative social response to the "here and now" of Colombia's social, economic, labor, and educational contexts.

\section{Colombia: A Hybrid Society}

In Colombia, poverty in its different dimensions coexists with policies that promote and embrace the latest communication and information technologies available (República de Colombia, Departamento Nacional de Planeación, 2000). To understand this contradiction, however, one must first identify the principal characteristics and contradictions of our society.

Colombia is currently in the grip of an armed conflict. Guerrilla and paramilitary forces have created generalized and widespread violence that has displaced large segments of Colombia's rural population into the nation's cities, creating perilous conditions of urban poverty. Drug trafficking has contributed greatly to this dire situation as well as to the environmental degradation of great expanses of farmland. Although Colombia enjoys an enviable geographical location and is blessed with possibly the greatest biodiversity on the planet, most of its people live in poverty.

To place the Open University Center (OUC) of the Pontifical Javeriana University (Universidad Javeriana) into context, the demographic characteristics of Colombia will be outlined in terms of population, employment, education, and poverty. For this purpose, we will summarize information prepared by Colombia's National Planning Department.

According to official projections, by 2005 the country will have an estimated population of 46,039,144, of which $33,371,138$ will live in urban centers, and $12,668,006$ will live in rural areas. In 2000 , citizens age 17 to 24 numbered $6,385,636$; this number is projected to increase to $6,660,422$ by 2005 (Corredor, 2001, p. 2).

Compared to other Latin American countries, Colombia faces the most critical situation with respect to employment, a basic fundamental that affects national living standards and levels of poverty (Corredor, 2001, pp. 7-8). Between 1993 and 1999, the national employment rate dropped from 53 to 50 percent, whereas the unemployment rate increased from 7 percent in 1993 to 16 percent in 1999.

International Review of Research in Open and Distance Learning 
Particularly hard hit were women (from 11 to 22 percent) and rural populations (from 5 to 11 percent). In the third quarter of 2000 , the national unemployment rate reached 20 percent.

However, there are some positives to highlight. From 1993 to 1999, the national illiteracy rate declined from 10 to 8 percent. For example, urban illiteracy rates declined from 6 to 5 percent, whereas rural illiteracy rates remained constant at 18 percent.

During this time frame, 90 percent of children age seven to eleven attended school (in the lowest stratum of society the attendance rate was only 67 percent). Eighty-three percent completed primary education and 62 percent finished secondary school. However, according to Ministry of National Education figures, the quality of basic education remained flat and has failed to meet projected targets in terms of learning outcomes for different grade levels in spite of the advances listed above (Corredor, 2001, pp. 12, 16).

Fifty percent of Colombia's population currently lives below the poverty line. More significantly, in terms of malnutrition and sickness, 20 percent live below the line of indigence. A Geni coefficient of .57 reveals inequitable distribution of wealth, with poverty having the upper hand. In 1985, 46 percent of the population lacked at least one of the basic necessities. Although this percentage dropped considerably after 1985, a 1998 report revealed that one of every four persons (26 percent) still lacked at least one basic necessity, and one person out of every twelve ( 8 percent) lacked two or more basic necessities. Simply put, large numbers of nation's population are still living in misery (Corredor, 2001). Still, advances have been made, such as the positive increases made in the Indicator of Life Conditions (ICV in Spanish) from 60.0 in 1985, to 73.0 in 1998. Currently, the city of Bogotá reports the best ICV of 87.71 (Corredor, 2001, p. 26). However, according to the 1997 Index of Human Poverty (IPH), a measurement that reflects basic living standards and a life expectancy of age forty, the greatest deficiencies in Latin America were nonetheless recorded in Colombia with an IPH of 8.9. According to this index, more than 15 percent of the country's population lack clean water, medical care, will likely die prematurely, suffer malnutrition in children under five years of age, and experience high illiteracy rates among adults age fifteen or older. Another factor that greatly exacerbates this index is the reality that in recent years, Colombia has been gripped in a continuous state of war.

In spite of the foregoing, Colombia's population is nonetheless characterized as being hardworking, seeking intellectual and economic improvement, proud of their cultural heritage, and desirous of peace and better living conditions. For all of its enormous contradictions and pitfalls, Colombia remains open to the world and strives to incorporate modern-day scientific and technological advances into its culture. Built upon a foundation of indigenous and Hispanic inheritance, Colombia is a hybrid culture that boasts of many positive elements that are important to explore, one of which is its education system.

International Review of Research in Open and Distance Learning 
According to the National Department of Planning, Colombia has of over 100,000 schools, 470,000 teachers, and 9.8 million students. In contrast to other countries in the region, participation in private education is high with enrolment growth rates of approximately 20 percent in primary schools, 32 percent in secondary education, and 67 percent in higher education.

According to current figures from the Colombian Institute for the Development of Higher Education (ICFES), the country has 306 registered higher education institutions, of which 57 are technical schools, 83 university institutions, 52 professional schools, 14 special purpose schools, and 100 universities. Sixty-one higher education institutions offer 571 programs, principally in the following fields: education (291); economic and administrative sciences (43); basic sciences (31); medicine (13); environmental and rural studies (13); and social sciences (11) (Centro Universidad Abierta, 2001).

Colombian universities in general, and the Universidad Javeriana in particular, are fully cognisant of the role they play in addressing and resolving many of society's problems. Since its establishment, the Open University Center (OUC) of the Universidad Javeriana has sought to provide educational opportunities to the nation's most vulnerable population, thereby contributing to enhancement of their quality of life.

In this context, we will now survey the current offering of distance education programs, specifically in the area of education, a field in which the OUC has specialized during its 29 years of operation. Currently, the OUC is concentrating principally on undergraduate programs (221 by distance and 51 semi-face-toface) and postgraduate programs at the level of specialization (61 semi-face-toface and 43 by distance) (OUC, 2001).

\section{The Open University Center (OUC) in the Context of a Hybrid University}

With respect to the different and coexisting educational modalities and pedagogical structures, the Universidad Javeriana can be considered a hybrid university. On one hand, the University is fundamentally a conventional face-to-face institution, in terms of its academic culture and administrative structure. Study takes place on the University's main campus and classes are offered and completed on a pre-determined schedule. Within this traditional university setting, however, and in accordance with liberating and humanistic principles to which it adheres, the OUC has designed and consolidated a new modality of distance education that promotes the schema of self-management, an educational concept that is fundamentally different from the rest of the university.

In contrast to conventional instructors, OUC teachers carry out through mediated distance education technology, programs of instruction that reflect the 
University's social commitment. Curricula are constructed on the basis of flexible conceptual axes, which adhere to criteria of excellence common to all conventional university programs. Additionally, the OUC system of evaluation goes beyond basic conceptual mastery to include project proposals initiated by students. OUC has established a normative system that makes possible an academic organization and supportive processes that, due to current conditions of social unrest in our country, is in a perpetual state of construction and reconstruction.

OUC has developed a decentralized administrative system designed to serve students in distant locations and communities. Even in areas without basic services such as electricity, the OUC has implemented viable administrative procedures for registration, admission, timely dispatch of course materials, and ultimately graduation ceremonies.

One of the OUC's most important achievements, however, has been the development and consolidation of a distance education model premised on the ideal of regarding students as initiators of positive change within their particular community. To achieve this goal, OUC has developed flexible curricula reflective of educational needs of the population at whom it is targeted. Central to the development of curricula is the treatment of the students as autonomous adults, capable of self-directed learning within the context of enriched learning environments that enhance interaction and make possible cooperative learning processes.

The distance learning model described above draws upon four dimensions: (1) Strategies to facilitate interaction, among which the tutorial is the most frequent form of instruction. Strategies also include mechanisms that promote self-education. (2) A combination of media selected to enhance learning experiences on different cognitive levels is sought to responds to the demands of both course content and student working conditions. (3) Evaluative strategies are employed to form baseline-learning outcomes, ranging from traditional face-to-face evaluation where students attend regional instructional centers, to open evaluations administered to students at a distance using reading materials. (4) Study projects (research and involvement) to develop critical and creative competencies relevant to student reality and daily routine.

As offered by the OUC, six fundamental aspects characterize distance education:

1. Democratization of knowledge: Distance education provides universal access to educational opportunities that otherwise could not be achieved using traditional campus based means. This modality promotes development of pluralism, mutual respect, tolerance of opinions, consensus, participation, and other normative values essential to the efficient operation of democratic systems.

International Review of Research in Open and Distance Learning 
2. Context of knowledge: A fundamental social function is to accommodate student's cultural needs and worldviews, achieved via curricular design and the subsequent assimilation of knowledge by students.

3. Objectification of knowledge: This is a process through which a given society places and consigns its knowledge in "objects" independent of time and space of whoever possesses the said knowledge.

4. Research: Distance education puts in to context and appropriates knowledge on the basis of underlying realities.

5. The organizational conception: The logic of the administrative and academic processes of distance learning yields a series of learning factors that are structurally unattainable in conventional face-to-face education.

6. Systematic use of information and communication: Distance education administrative and academic systems and processes must be of sufficiently large scale to ensure timely, accurate and reliable distribution of information.

\section{Socially Sensitive Mission}

The social mission of the OUC of the Universidad Javeriana is to create, organize, and disseminate different curricula, programs, and projects that are relevant to, and address, the contemporary educational needs of Colombians by providing access to those who would not otherwise engage in conventional higher education. To accomplish this mission, the OUC uses the following processes.

- As per the Javeriana Educational Project's mission, provide universal access to education through the different curricula.

- Encourage and promote distance education research.

- Use and develop new technologies to modernize and enhance the different processes of Colombia's distance education system. ¡SUP ¿3.

\section{Historical Approach to the Open University Center}

The OUC can trace its origin to the 1972 television program: "Educators of New Men." Based on this experience, the Faculty of Educational Sciences created 
the Javeriana Model of Distance Education in 1974, one that incorporates the pedagogical elements required to provide university options that enables student teachers to update their qualifications. Other programs followed: (1) degree program in Primary Basic Education in 1983; (2) Bachelor's degree in Pedagogy in 1984; (3) specialization in Religious School Education and Catechism in 1998; (4) Master's degree in Education in Advanced Pedagogy for Coexistence in 1999; (5) the specialization in the Prevention of Child Abuse and the degree in Basic Education with Emphasis in Humanities and Spanish Language in 2000. Since 1994, the Universidad Javeriana has organized and hosted four bi-annual International Symposiums of Distance Education in Bogotá, to address issues of interest for the field.

On May 24, 1995, the Open University Program became the Open University Center (OUC), and was given the immediate responsibility for operational planning, management and administration of undergraduate, graduate, and other academic distance education programs developed by the Universidad Javeriana. The OUC now has financial responsibility for these programs, as well as for coordination of all the University's distance education activities.

\section{Structure of the Open University Center in Relation to Colombia's Culture and Context}

The OUC operates with two governing councils. In accordance with the statutes and general regulations of the Universidad Javeriana, the DE counsel is responsible for orientation and general management, as well as integration of teaching, research, and service functions. The Council of the OUC is a central management advisory team comprised of a General Director, three Deputy Directors in Academic, Social and Administration, Associate Directors, Academic Program and Unit Directors, two Regional Center Directors, plus tutor and student representatives.

Answering to the Academic Vice-Rector of the Universidad Javeriana, this management team sets the policies of the OUC and is responsible for planning, organization, management, and control of the academic and administrative processes at both the central and regional levels. The following committees advise the central management: Curricula, Research, Library, and Web Pages.

With central management, the Academic Deputy Director determines the pedagogical policies and services (curricula, educational materials, evaluation, and tutoring) for OUC academic programs. The Office of the Deputy Director, Administrative, develops and establishes administrative policies and procedures for finance, personnel, physical plant, and materials distribution. This Director also oversees both the Educational Media Design Unit and the Computer Systems Unit.

International Review of Research in Open and Distance Learning 
The Office of the Deputy Director of Social Action is responsible for encouraging an organizational climate that supports and enhances student and employee performance. This Office is also responsible for the Community Promotion Unit, a team that communicates and promotes OUC activities in local communities, as well as facilitates environments that encourages students to participate in the two-way flow of communication for the underlying purpose of creating vigorous community values.

OUC also works to maintain good relations with various academic and scientific communities via the following networks: International Council for Distance Education (ICDE), Consorcio Red de Educación a Distancia (CREAD), Asociación de Televisión Educativa Iberoamericana (ATEI), and Asociación Colombiana de Instituciones de Educación Superior con Programas a Distancia (ACESAD).

\section{Subsystems: Students}

According to the OUC mission, students are the most important subsystem. Students are the razón de ser of every academic, social, and administrative activity at the university, simply because the professional education of undergraduate and postgraduate students contributes to the needs of the Colombian society. Currently, 5,316 undergraduate and 190 postgraduate students are enrolled. Broken down by program of studies, student enrolment is distributed as follows: 4,033 in the Licenciatura in Basic Primary Education and 1,283 in the Licenciatura in Basic education with Emphasis in Humanities and Spanish. Of the postgraduate students, 154 are enrolled in the Specialization in Religious School Teaching and Catechism, and 36 are enrolled in the Specialization in Prevention of Child Abuse. The average age of students enrolled in these programs is 43 .

For 20 years, the OUC has offered its programs to the entire Colombian population through 17 regional centers and 13 support centers. In 1999, the OUC operated in 729 municipalities with a total of 5,664 active students. The OUC boasts of 19,768 graduates to date.

\section{Subsystems: Programs}

Licenciatura in Basic Primary Education: This is an undergraduate degree offered by the OUC, the objective of which is to provide holistic distance education opportunities for education practitioners so that in accordance with current ethical considerations (e.g., the promotion of respect and mutual dignity), graduates may contribute to the positive transformation of Colombian society through education. Via its focus on instruction, research, and service, this program is designed to achieve the following objectives:

International Review of Research in Open and Distance Learning 
- A personalized pedogogal approach provides professional development opportunities for basic and primary education teachers.

- Contribute to the qualitative improvement of primary education by having teachers trained to identify and respond to the educational needs of children living in the country's more impoverished regions.

- Formally recognize teachers as professionals through the provision of professional development opportunities that help increase their level of expertise.

This 16-semester program is comprised of the following: Pedagogical Foundations, Pedagogical Methodology, and Pedagogy of the Sciences. Each area is composed of various subjects, including a series of courses developed using a multimedia system consisting of educational material, individual work, face-toface sessions, tutorials, and study-group projects called Interaction Nuclei.

The curricula of the Licenciatura offers a set of experiences designed to enable educators to:

- Communicate effectively on both public and interpersonal levels, helping teachers develop a sense of individual autonomy, while remaining responsive to their respective historical and geographical contexts.

- Identify and analyze cognitive and learning processes to help students to socialize and interact more effectively.

- Build skills and knowledge competencies in planning processes such as curricula development, instructional design and community development.

- Conduct research in specialized areas such as: creative learning, adaptation of curricula, and the development of educational content designed to address the needs of students and the community.

- Develop attitudes of commitment toward moral, religious, aesthetic, civic, and political standards.

- Generate changes in the educational system, such as the creation of a more just and humane Colombian society.

Licenciatura in Basic Education with Emphasis on Humanities and Spanish: This Licenciatura gives teachers conceptual tools and experiences premised on holistic education practices and continuing pedagogical research, a process that helps teachers to think critically about school mechanisms, the study of Spanish, and of their own discursive practices. This program seeks to achieve the following objectives:

International Review of Research in Open and Distance Learning 
- Articulate concepts from the different fields of study, grounding them within the context of their personal and academic life.

- Advance new educational forms. Instruction in the administration and mediation of social processes that facilitate student achievement.

- Promote investigative and innovative education via pedagogical research and language development skills.

- Provide relevant research approaches to the use of new multimedia in such fields as: computing science, business, arts, and languages.

Students who are engaged in this 12 -semester program proceed through three distinct stages:

- Initiation Stage: Concepts that introduce students to the principles and criteria of curricular construction help make the "rules of the game" explicit.

- Common Stage: Concepts considered fundamental to basic education teachers are offered in such a manner that problematizes the school institution, thereby contributing to pedagogical discourse.

- Emphasis Stage: Concepts are presented that relate specifically to $\mathrm{Hu}-$ manities and Spanish.

Specialization of Religious School Teaching and Catechism: This is a postgraduate degree that provides teachers of religious schools, clerics, catechism instructors, and persons interested in spiritual growth, with a solid theological, pedagogical, and research education. In turn, this education permits students to both certify their educational activities and become agents of change within the context of their religious affiliation and communities.

The program seeks the following objectives:

- Educate religious teachers and instructors so that they can instil in themselves, their families, and community, moral values of humanity, tolerance and solidarity as based on the Gospel.

- Provide clerics with the education necessary to help establish catechistic leadership within their parishes and other Church areas.

- Reinforce theological education principals in students that will enable them to: explain and understand their faith in Jesus Christ; build a foundation for their educational practice and catechism as required by the mission of Christian teachers and Church catechists; know and utilize pedagogical media, catechistic models and specific didactic strategies 
Open University Center of the Pontifical Javeriana University, Colombia.

of religious school and catechism instruction; provide access to information and documentation based on reflection and analysis; and examine the methodological design of educational research, permitting students to describe diagnostic evaluative processes of their reality as Christian educators and redefine methodological and practical processes to improve religious school instruction and catechism.

Among the curricular components of this six-semester program are:

The Postgraduate Specialization in Prevention of Child Abuse: This specialization has the following objectives:

- Contributes to the understanding of child abuse and intervention techniques designed to identify and positively transform power relationships between adults and children.

- Promotes professional expertise in the field of child abuse prevention (this helps the University realize its social mandate, regionally and nationally).

- Utilizes conceptual and operational references that permit re-definition of child abuse issues, and provide subsequent solutions to previously hidden instances of child abuse.

- Conducts applied research in areas such as alternative intervention, construction of knowledge and transformation of realities.

- Grounds explanations within the context of students' culture, experiences and worldviews so they can identify, plan, and execute viable intervention strategies.

This six-semester program is composed of the following core elements:

- Infancy: This element focuses on the concept of infancy, from both current and historical perspectives.

- Representations: This element focuses on the construction of shared beliefs and the appropriation and measurement as a basis for imagination, expectations, beliefs, fantasies, and practices within the context of intersubjective relationships.

- Bonds: This element encourages reflections about ways in which human beings form bonds and interact with each other by emphasizing emotional ties, as well as consequences of forming relationships.

- Space for education: Because this specialization focuses preventive intervention, this element examines the contextual role played by families, education, and the workplace, along with the role the state plays in the formulation and execution of childhood policies.

International Review of Research in Open and Distance Learning 
- Research/Intervention: This element surveys research and intervention models.

\section{Continuing Education}

The OUC also offers non-credit courses and diplomas through its Continuing Education Unit, with the underlying objective of providing educational alternatives for university, industry, and professional development in the distance modality. Charged with the mandate of planning, disseminating, and developing training programs that correspond to the needs of Colombians living in the country's diverse regions, the Unit organizes and works with interdisciplinary teams to meet its objectives. For instance, the Unit seeks to promote lifelong education amongst the country's education professionals, thereby creating an overall positive effect on regional and national levels.

\section{Projects Unit}

The Projects Unit is a joint academic/administrative venture that focuses on the development of distance education projects. This unit articulates and shares the University's academic experience with other spheres of Colombian society. It also provides educational alternatives, principally in the field of distance education, to other academic institutions, public and private sector organizations, and to marginalized populations seeking to better their lives. It also conducts distance education research, primarily in the area of education processes. The unit has developed a variety of strategies designed to develop and strengthen its relationships and reputation at a regional, national and international level. At the OUC, for example, the Projects Unit has entered into agreements with UNICEF, the Foundation for Education Superior, the Company of Jesus for a Program for Peace, the National Conference of Catholic Bishops, the National Police, the Executive Secretary of the Andrés Bello-SECAB, University of Chile, the International Colombia Resources Corporation (INTERCOR), the Saldarriaga Concha Foundation, the British Council, and the British Embassy.

\section{Subsystem: Regulations}

The General Statutes and Regulations of the Universidad Javeriana govern the OUC. There are also regulations pertaining to specific aspects of distance education such as open admissions, tutoring, follow-up and evaluation.

International Review of Research in Open and Distance Learning 


\section{Subsystems: Infrastructure and Technology Base}

The OUC's administration is headquartered on the main campus of Universidad Javeriana, in the city of Bogotá. Three supporting units constitute the technological infrastructure and foundation of the OUC: Media Design Unit, Computing Systems Unit, and the Regional Centers. For example, the Media Design Unit produces course materials using print, audiotapes, television, and more recently, multimedia.

The Computing and Systems Unit provides the OUC with a reliable information and communication infrastructure including the design and programming of systems required for the effective administration of academic programs in functional areas such as registration, finance, administration, and its course offerings. Software used includes both legacy (4th Dimension, Oracle, and Access) and break though (Internet and Web) technologies, systems that give some students access to multi-media content such as video-conferencing, virtual text, and e-books delivered via both Mac and PC platforms.

Currently there are 17 regional centers located across Colombia: (Antioquia, Atlántico, Boyacá, Caldas, Caquetá, Cauca, Córdoba, Cundinamarca, Chocó, Guajira, Guapi, Huila, Llanos Orientales y Amazonía, Nariño, Santander, Tolima and Valle del Cauca). By anticipating the educational needs, interests, and expectations of its local citizens, each Regional Center acts as an interpreter of its own local cultural milieu and contributes to the overall improvement and quality education at a grassroots level. By personalizing the OUC's distance education system, the regional centers address student needs. Building upon specific, collective and individual experiences, students achieve growth through "nuclei of interaction" group-study projects mentioned previously.

\section{Performance Indicators}

Because a systematic follow-up has yet to be conducted, we only have partial indicators of the social impact of the OUC's educational programs at this time. Because a data vacuum exists with respect to our programs vis-à-vis our graduates' professional performance, it is difficult to accurately determine the intended and unintended consequences of the OUC's academic programs.

\section{The Universidad Javeriana: Implications and Relation- ships}

In spite of the advances of the OUC, there remains a generalized ignorance of distance education throughout the organization. Indeed, distance education is still considered by many to be an inferior form of education, a mode not on par with

International Review of Research in Open and Distance Learning 
traditional forms of face-to-face university education. However, with advances in information and communication technologies becoming more apparent, this perception is starting to change; distance education is now viewed by many as a way to realize changes needed to achieve the ideal of "virtual" education. As a result, the OUC is becoming more widely recognized for its pedagogical model based on distance education processes - processes that nonetheless conform to and complement the principles and values of the Universidad Javeriana. Given the academic experience and the presence of the Center, it has become a visible champion and advocate of advanced education via distance education in both urban and rural settings. Working collaboratively with different faculties in the adaptation, design, and launch of new distance education projects, the OUC helps ensure that the educational needs of Colombia's diverse population are met, particularly working adults and marginalized groups for whom education opens up new possibilities for improvement of the quality of their lives.

\section{The Future of the University and the Future of Virtual Education}

The OUC has developed and consolidated a distance education model that is considered its main strength. Hence, the Center is in a position to contribute to university-wide development of virtual education solutions, principally by building upon the theoretical and practical constructions it has already achieved. Viewed as an alternative to traditional forms of university work, professors can now utilize pedagogical thought as a fundamental criterion upon which to make decisions related to the implementation of modern virtual teaching technologies. The Center strives to engage in critical utilization of such technologies in order to, on the one hand, facilitate teaching, and on the other, guide academic decisions in the quest to accomplish authentic university work (Parra de Marroquín \& Barbosa, 2001, p. 2).

For the OUC, learning ideally takes place in an environment that: (1) is responsive to a social and cultural context (justification); (2) addresses specific necessities and issues (purposes); (3) is based on academic and cultural knowledge (knowledge); (4) involves teams in the determination and use of technology; and (5) facilitates the formation of virtual social groups (Parra de Marroquín \& Barbosa, 2001, p. 4).

\section{Future Consequences}

The major challenge facing the OUC will be to continue providing open study opportunities that will enable its students to elevate their standard of living and rise above poverty. However, to achieve this goal, the OUC must manage

escalating program design and delivery costs on the one hand, and respond to

International Review of Research in Open and Distance Learning 
advances in new information and communication technologies, on the other. It is a delicate balancing act. Therefore, the OUC is collaborating with other public and private universities and organizations, to build a viable communication network on a national level that will address the needs of Colombia's most impoverished populations. Like in other Latin American countries, the OUC faces the challenge of proposing and developing a range of undergraduate and postgraduate educational alternatives in all disciplines. In the same manner, it faces the challenge of proposing and developing a wide range of alternatives education solutions - both undergraduate and postgraduate - that address the needs of our country and our people. 


\section{References}

Canclini, Néstor García (1990). Culturas híbridas: estratégias para entrar y salir de la modernidad. México: Grijalbo/Consejo Nacional para la Cultura y las Artes.[Brazil]

Corredor, Lina, Claricia (2001). Investigación de Factibilidad. Análisis de Necesidades y Tendencias. Centro Universidad Abierta.

National Planning Department (2001). Sistema de Indicadores Socio-Demográficos para Colombia. [Online] Available at: http://www.dnp.gov.co/.

República de Colombia. Departamento Nacional de Planeación. (2000) "Agenda de Conectividad," Documento Conpes 3072. Bogotá, Colombia. [Online] Available at: http://www.dnp.gov.co/ArchivosWeb/ Direccion_Infraestructura _Energia/Telecomunicaciones/Documentos/Conpes_3072_Agenda percent20de percent20Conectividad.pdf.

Centro Universidad Abierta. Investigación de Factibilidad. Unidad de Proyectos. (2001). Listado $\mathrm{N}^{\circ} 10$ : Número de programas por país donde se ofrecen, Listado $\mathrm{N}^{\circ}$ 9: Total de programas por países y campos de conocimiento y Listado $\mathrm{N}^{\circ} 10$ : Número de programas por país donde se ofrecen.

Parra de Marroquín, Omayra and Barbosa, Juan Carlos (2001). El Diseño Pedagógico con la Inserción de las Tecnologlías de Información y Comunicación. Paper presented at the Conferencia Internacional sobre Educación, Formación y Nuevas tecnologías: Virtual Educa. Madrid, Spain.

Parra de Marroquín, Omayra and Barbosa, Juan Carlos (2001). El Diseño Pedagógico con la Inserción de las TIC. Paper presented at the Conferencia Internacional sobre Educación, Formación y Nuevas tecnologías: Virtual Educa. Madrid, Spain.

Citation Format

Parra de Marroquin, Omayra \& Claricia Corredor Moyano, Lina (January, 2002) Open University Center of the Pontifical Javeriana University, Colombia.. International Review of Research in Open and Distance Learning: 2, 2. http://www.icaap.org/iuicode?149.2.2.3 